Check for updates

Cite this: Nanoscale Adv., 2019, 1, 2311

\title{
A highly sensitive printed humidity sensor based on a functionalized MWCNT/HEC composite for flexible electronics application $\dagger$
}

\author{
Vikram S. Turkani, (D) ${ }^{* a}$ Dinesh Maddipatla, (D) a Binu B. Narakathu, ${ }^{a}$ Tahseen S. Saeed, ${ }^{\text {b }}$ \\ Sherine O. Obare, ${ }^{b}$ Bradley J. Bazuin ${ }^{a}$ and Massood Z. Atashbar ${ }^{a}$
}

A novel functionalized multi-walled carbon nanotube (FMWCNT)/hydroxyethyl cellulose (HEC) compositebased humidity sensor was successfully developed for humidity monitoring applications. FMWCNTs were synthesized by covalently functionalizing multi-walled carbon nanotubes (MWCNTs) in a mixture of sulfuric and nitric acid to enhance their hydrophilicity. The FMWCNTs were characterized using transmission electron microscopy, Raman spectroscopy, Fourier transform infrared spectroscopy and dispersion analysis to verify the presence of functional hydroxyl and carboxyl groups. A FMWCNT/HEC $(1: 6 \mathrm{w} / \mathrm{w})$ composite ink was formulated using the solution blending technique with $2.5 \mathrm{wt} \%$ FMWCNTs. A multi-layered humidity sensor was fabricated using additive print manufacturing processes on a flexible polyethylene terephthalate (PET) substrate. Screen printing and gravure printing processes were used to deposit the bottom silver (Ag) electrode and FWMCNT/HEC sensing layers, respectively. The capability of the fabricated humidity sensor was investigated by measuring its resistive response towards relative humidity $(\mathrm{RH})$ varying from $20 \% \mathrm{RH}$ to $80 \% \mathrm{RH}$. As the $\mathrm{RH}$ was increased from $20 \% \mathrm{RH}$ to $80 \% \mathrm{RH}$ in steps of $10 \% \mathrm{RH}$ at $25{ }^{\circ} \mathrm{C}$, it was observed that the resistance of the printed sensor increased linearly. The printed sensor demonstrated resistance changes as high as $\approx 290 \%$ at $80 \% \mathrm{RH}$, when compared to its base resistance at $20 \% \mathrm{RH}$. A sensitivity and a response time of $0.048 / \% \mathrm{RH}$ and $\approx 20 \mathrm{~s}$ were obtained for the printed sensor, respectively. The results thus demonstrated the feasibility of employing additive print manufacturing processes to develop a highly sensitive sensor for humidity monitoring applications.

\section{Introduction}

Over the years, the need for monitoring humidity in the automobile, medical and food industries has become a growing requirement. ${ }^{1-4}$ Further, the maintenance of ambient conditions within human habitats for optimum comfort has often been influenced by humidity, thus making it one of the vital parameters that needs to be monitored. ${ }^{5}$ Owing to this importance, humidity measurement has been extensively studied and, accordingly many researchers have developed various types of humidity sensors based on different sensing principles and diverse hygroscopic materials. ${ }^{6,7}$ Humidity is measured as absolute humidity (AH) and relative humidity (RH) which provide the true value and relative value (in terms of pressure) of water vapor content in a given volume of air, respectively. ${ }^{6} \mathrm{RH}$

\footnotetext{
${ }^{a}$ Department of Electrical and Computer Engineering, Western Michigan University, 4601 Campus Drive, Kalamazoo, Michigan-49008, USA. E-mail: vikramshreeshail. turkani@wmich.edu; Tel: +12692763148

${ }^{b}$ Department of Chemistry, Western Michigan University, 1903 Western Michigan Avenue, Kalamazoo, Michigan-49008, USA

$\dagger$ Electronic supplementary information (ESI) available: Experimental details related to the functionalization of MWCNTs. See DOI: 10.1039/c9na00179d
}

based sensors are more commonly used for monitoring humidity due to their ease-of-use and cost-efficiency. ${ }^{6}$ They have been extensively used in applications involving indoor air quality, human comfort issues and research laboratories. ${ }^{6}$ Therefore, the development of humidity sensing systems that employ novel RH sensors is of utmost importance.

Resistive type RH humidity sensors are the most commonly implemented type in the industry, as they are much easier to integrate and use relatively simpler electronics to monitor and control ambient humidity. ${ }^{8}$ Most of the resistive type humidity sensors are fabricated by coating hygroscopic polymers including polyimide, ${ }^{8-10}$ co-polymerized PMMA/PMAPTAC ${ }^{12}$ and polyelectrolyte ${ }^{13}$ as the humidity sensitive films. ${ }^{12}$ However, these devices are typically slow and suffer from a relatively longer response time (105 s). ${ }^{14}$ Moreover, these sensors have lower humidity detection limits $(30-42 \% \mathrm{RH})$, making them impractical for use in many industrial and domestic applications. ${ }^{8,15}$ Therefore, research has been focused on the development of novel materials for resistive type humidity sensors to overcome the drawbacks associated with polymeric based resistive type humidity sensors. Owing to their large surface area to volume ratio and hollow cylindrical nanostructure, ${ }^{16}$ multiwalled carbon nanotubes (MWCNTs) have been 
extensively employed for sensing various molecules adsorbed on their surface. ${ }^{17,18}$ Research has been reported on MWCNT based resistive type humidity sensors. Liu et al. reported a resistive type humidity sensor based on pristine MWCNT networks and demonstrated its capability to sense a broad range of relative humidities (25\% $\mathrm{RH}$ to $85 \% \mathrm{RH}$ ) with good linearity and an excellent response time of $3 \mathrm{~s} .{ }^{19}$ However, this device suffered from a low sensitivity of $0.5 \% / \% \mathrm{RH}$ towards humidity sensing. ${ }^{19}$ To improve the sensitivity of the MWCNT based humidity sensor, Cao et al. $^{20}$ chemically treated the surface of MWCNTs and compared the humidity sensing characteristics of both chemically treated and untreated MWCNTs. It was observed that the former had greater sensitivity than the latter due to the presence of hydrophilic functional groups on the surface of the chemically treated MWCNTs. ${ }^{20}$ Thus, MWCNTs are promising as humidity sensitive materials. However, more efforts are needed towards the development of novel MWCNT based, highly sensitive, resistive type humidity sensors.

Conventionally, humidity sensors have been manufactured on rigid structures like glass or ceramics using techniques such as photolithography and sputtering. ${ }^{21,22}$ These techniques are relatively expensive and time consuming as they require high vacuum, large power density, and a high temperature environment. Moreover, the rigid nature of the substrates prevents their use in applications which require mechanical flexibility and conformal form factors. To overcome these limitations, additive print manufacturing processes such as screen, inkjet, gravure and flexography can be used for the development of cost efficient, flexible and conformal humidity sensors. These additive print manufacturing processes have already enabled an emerging field called flexible hybrid electronics to develop novel, cost-efficient electronic devices for applications that demand flexibility and conformability. Accordingly, many researchers have actively employed these processes for the development of RFID tags, ${ }^{\mathbf{2 3 , 2 4}}$ sensors, ${ }^{25-34}$ solar cells, ${ }^{35,36}$ antennas ${ }^{37}$ and circuits. ${ }^{38,39}$ In a recent study, a CNT based humidity sensor fabricated using two printing processes, screen and gravure printing, was reported. ${ }^{\mathbf{4 0}}$ In addition, Xie et al. also reported an inkjet printed MWCNT based humidity sensor. ${ }^{41}$ Although the printed sensors in both the cases responded towards ambient humidity, there is still a need to improve their sensitivity. Therefore, the use of additive print manufacturing processes to develop highly sensitive humidity sensors employing MWCNTs and/or MWCNTs/polymer composites is envisioned to advance the field of humidity sensing.

In this work, a multi-layered functionalized multi-walled carbon nanotube (FMWCNT)/hydroxyethyl cellulose (HEC) composite-based humidity sensor was developed using additive print manufacturing processes on a flexible polyethylene terephthalate (PET) substrate. MWCNTs were subjected to acid functionalization in a mixture of sulfuric and nitric acid. Transmission electron microscopy, Raman spectroscopy and Fourier transform infrared spectroscopy were performed to verify the functionalization of MWCNTs. Screen printing, a push through process was employed to deposit the electrodes in an interdigitated structure. The FMWCNT/HEC composite ink was formulated and deposited on the electrodes as the humidity sensing layer using gravure printing. The performance of the printed humidity sensor was investigated by measuring its resistive response towards relative humidity $(\mathrm{RH})$ varying from $20 \% \mathrm{RH}$ to $80 \% \mathrm{RH}$ at a constant temperature of $25{ }^{\circ} \mathrm{C}$.

\section{Experimental}

\subsection{Chemicals and materials}

A flexible PET film (MELINEX® ST730) from DuPont Teijin Films was used as the substrate. Conductive Ag ink (AG-800) from Applied Ink Solutions was used for the electrodes. The conductive filler for the sensing layer was MWCNTs, with diameters and lengths of 20-30 $\mathrm{nm}$ and 10-30 nm, respectively (US Research Nanomaterials, Inc., US4039, purity > 95 wt\%). Analytical grade $95 \%$ sulfuric acid $\left(\mathrm{H}_{2} \mathrm{SO}_{4}\right)$ and $70 \%$ nitric acid $\left(\mathrm{HNO}_{3}\right)$ from Sigma-Aldrich Chemical Company were used for the functionalization of the MWCNTs via acid treatment. Hygroscopic HEC (Cellosize ${ }^{\mathrm{TM}}$ Hydroxyethyl Cellulose EP-09, DOW chemical company) and polyvinylpolypyrrolidone (PVPP) polymer (ViViPrint ${ }^{\mathrm{TM}}$ 540, Ashland Performance Materials) were used as the polymer matrix and binder in the FMWCNT/HEC ink, respectively. Acetone, from Sigma-Aldrich Chemical Company, and de-ionized (DI) water were used as the cleaning solvents for the Ag and FMWCNT/HEC inks, respectively. The electrical connections for the printed sensor were made using contact flat flex interconnects (Model no. 1-88997-2) from TE Connectivity AMP Connectors. The headers of these interconnects were connected using male to female jumper wires (Model no. 1568-1511-ND) from SparkFun Electronics.

\subsection{Functionalization of MWCNTs}

The MWCNTs were subjected to a covalent functionalization process which involves surface modification of the MWCNTs by incorporating hydrophilic substituents onto the exterior MWCNT sidewalls ${ }^{42}$ (Fig. S1 $\dagger$ ). The aim of the functionalization process was to improve the hydrophilicity of MWCNTs besides aiding their dispersion in aqueous medium. ${ }^{\mathbf{4 3 4 4}} 2 \mathrm{~g}$ of MWCNTs were added to a $3: 1(\mathrm{v} / \mathrm{v})$ mixture of $\mathrm{H}_{2} \mathrm{SO}_{4}$ and $\mathrm{HNO}_{3}$, respectively and the mixture was refluxed at $140{ }^{\circ} \mathrm{C}$ using continuous magnetic stirring for 1 hour. ${ }^{11}$ The mixture was allowed to cool down to room temperature after the reflux. Then, the obtained mixture was titrated against $\mathrm{NH}_{3} \mathrm{OH}$ until a pH of 5.5 was attained. ${ }^{44}$ The neutralized solution was then vacuum filtered to separate the FMWCNTs using $0.2 \mu \mathrm{m}$ pore size polytetrafluoroethylene membrane filters. Finally, the FMWCNTs were washed with DI water several times and dried for 12 hours at $140{ }^{\circ} \mathrm{C}$.

\subsection{Characterization of the FMWCNTs}

Transmission electron microscopy (TEM) and Raman spectroscopy were used to obtain morphological information and to determine the degree of functionalization, respectively, of the MWCNTs before and after acid treatment. A JEOL 100 CXII TEM with an accelerated voltage of $200 \mathrm{kV}$ was used to record 
the TEM micrographs and analyze the morphology of MWCNTs. Two samples were prepared by dispersing the MWCNTs in ethanol and the FMWCNTs in DI water. The prepared samples were dropped on a carbon coated 200-mesh copper grid for imaging.

The experimental setup for Raman spectroscopy is shown in Fig. S2. $\dagger$ The MWCNT and FMWCNT samples were placed in a sample holder (PA-SH02, Inphotonics Inc). A laser source in the near infrared region with a wavelength of $785 \mathrm{~nm}$ was used to excite the samples using a Raman probe from Inphotonics Inc. with an integration time of 3 seconds at 300 mW. Raman analysis was performed for both the MWCNTs and the FMWCNTs, and a comparison was made to obtain the degree of functionalization of the MWCNTs after acid treatment. ${ }^{44}$ A spectrometer (QE 6500) from Ocean Optics Inc. was used to obtain the Raman spectra. The Raman spectra were then analyzed using Spectra Suite Software from Ocean Optics Inc.

Fourier transform infrared spectroscopy (FT-IR) was performed to verify the presence of hydrophilic constituents on the surface of the FMWCNTs. Two samples, one with MWCNTs and another with the FMWCNTs, were prepared by mechanically mixing them with potassium bromide powder. The mixtures were pressed into discs and were placed in a ThermoFisher Nicolet iS5 spectrometer. The FT-IR spectra were analyzed using OriginPro software.

The dispersion analysis was performed on both MWCNTs and FMWCNTs to compare their suspension stability in DI water, thereby demonstrating the efficiency of functionalization. ${ }^{44} 0.125 \mathrm{~g}(0.5 \mathrm{wt} \%)$ of MWCNTs and FMWCNTs were dispersed in $25 \mathrm{~mL}$ of DI water. The solutions were stirred vigorously for 60 minutes and held for 5 days, which is a sufficient duration required to formulate the ink and fabricate the sensor.

\subsection{FMWCNT/HEC ink formulation}

The FMWCNT/HEC ink was formulated using DI water as the solvent. Fig. 1(a) shows the steps involved in the ink formulation. Initially, hydrophilic FMWCNTs (1.25 wt\% and $2.5 \mathrm{wt} \%)$ were added into the solvent, followed by magnetic stirring for 1 hour to ensure proper dispersion. General dispersion techniques such as bath and probe sonication were not considered as these techniques would result in excessive evaporation of the solvent. ${ }^{45}$ The FMWCNT/HEC composite for the ink was prepared using the solution blending technique. ${ }^{11}$ FMWCNT/ HEC composites with varying ratios $(1: 4 \mathrm{w} / \mathrm{w}$ and $1: 6 \mathrm{w} / \mathrm{w})$ were prepared for studying the humidity response. In addition to being a hygroscopic polymer, HEC is also an efficient dispersant in the ink system as it is completely water soluble and swells in the presence of water, thereby preventing agglomeration between the FMWCNTs. ${ }^{\mathbf{1 1 4 6}}$ The mixture was stirred for 16 hours to obtain homogeneity in the composite. Finally, PVPP was added and magnetically stirred for 3 hours to form the FMWCNT/HEC ink (Fig. 1(b). PVPP was chosen as a suitable binder due to its swelling behavior in water and its loading was restricted to $50 \mathrm{wt} \%$ FMWCNTs, maintaining a binder to filler ratio of $1: 2$. The TEM image of the FMWCNT/ HEC ink (Fig. 1(c)) shows the FMWCNTs embedded in the HEC polymer matrix.

\subsection{Assessment of the print compatibility}

The surface tension (ST) and contact angle (CA) of the formulated FMWCNT/HEC ink were measured to be 64.1 (dynes $\mathrm{cm}^{-1}$ ) and 56.2 (degrees) with a goniometer (First Ten Angstroms FTA200) using the pendant drop $\operatorname{method}^{49}$ and sessile drop method ${ }^{50}$ respectively (Fig. 2(a)). The surface energy (SE) of the PET was also measured to be 45.4 (dynes $\mathrm{cm}^{-1}$ ) with the goniometer using the Owens Wendt method. ${ }^{48}$ It was observed that

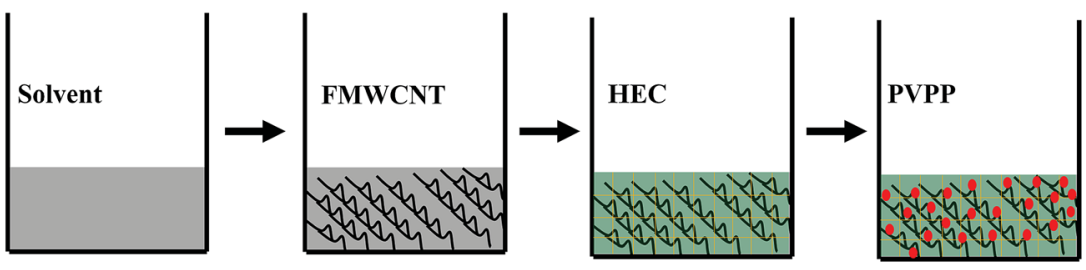

Stirring for $1 \mathrm{~h} \quad$ Stirring for $16 \mathrm{~h} \quad$ Stirring for $3 \mathrm{~h}$

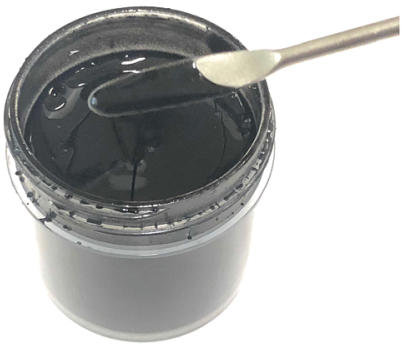

(b)

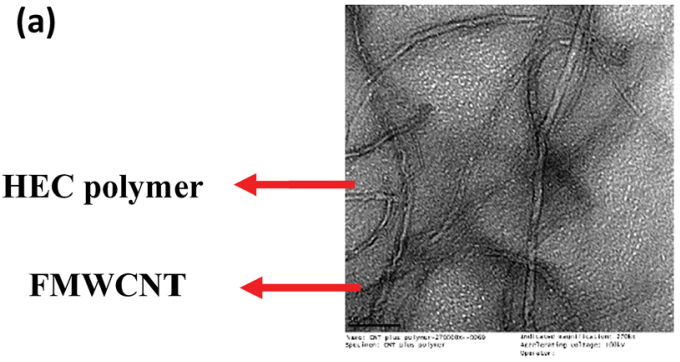

(c)

Fig. 1 FMWCNT/HEC ink formulation: (a) steps involved in ink formulation, (b) photograph of the FMWCNT/HEC ink and (c) the TEM image of the FMWCNT/HEC ink. 
Before adding surfactant

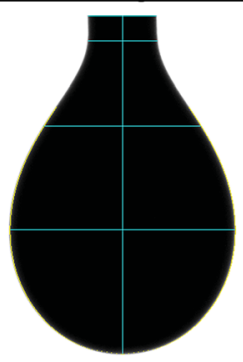

Surface tension: 64.1 (dynes $/ \mathrm{cm}$ )

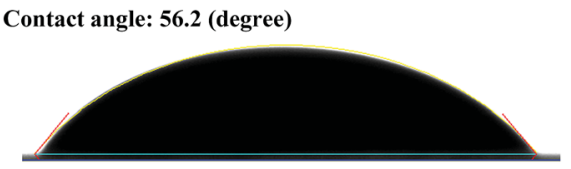

(a) $\underline{\text { After adding surfactant }}$

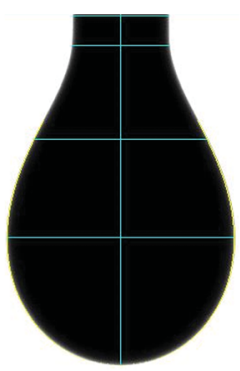

Surface tension: 23.8 (dynes/cm)

Contact angle: 22.16 (degree)

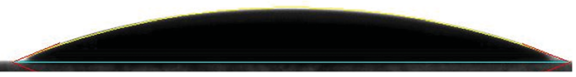

(b)

Fig. 2 Surface tension of the FMWCNT/HEC ink (a) before and (b) after adding the surfactant.

the ST of the ink was 18.7 units greater than the SE of the substrate. However, a good print compatibility between the printed layer and the substrate is obtained when the SE of the substrate is greater than the ST of the ink. ${ }^{47}$ This is because the SE of the substrate, which is the energy due to the intermolecular forces, should be able to break the resistance of the ink and to deform it into a new surface. ${ }^{47}$ The resistance offered by the ink, due to attractive intermolecular forces formed on its interfacial surface, is the ST of the ink. ${ }^{47}$ Therefore, 1 wt $\%$ Ecosurf тм (Dow Chemical Company) surfactant was added to the prepared FMWCNT/HEC ink and was magnetically stirred for 3 hours for reducing its ST. It was observed that the ST decreased to 23.8 (dynes $\mathrm{cm}^{-1}$ ), which is 21.6 units less than the SE of the substrate (Fig. 2(b)). Thus, it was concluded that the FMWCNT/HEC ink was print compatible with the PET substrate.

\subsection{Humidity sensor fabrication}

Fig. 3 shows the schematic of the humidity sensor. It consists of three layers: substrate, electrodes and a sensing layer. The sensor was designed with an overall dimension of $22 \mathrm{~mm} \times$

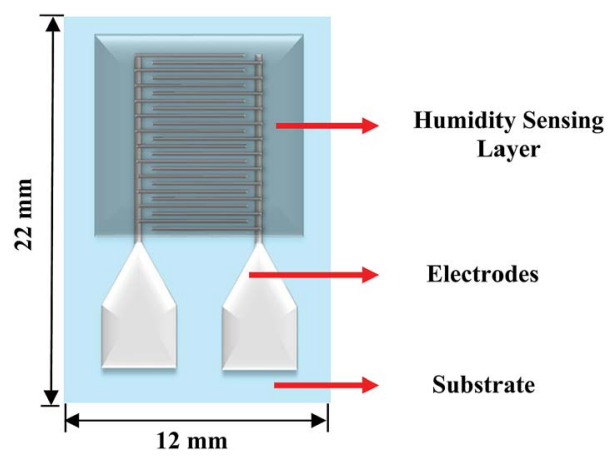

Fig. 3 Schematic of the humidity sensor (not to scale).
$12 \mathrm{~mm}$ in Adobe Illustrator ${ }^{\circledR}$ design software. The sensor consists of a pair of electrodes, with 24 interdigitated (IDT) fingers that are $5200 \mu \mathrm{m}$ long and $200 \mu \mathrm{m}$ wide, with a pitch of $400 \mu \mathrm{m}$. The sensing layer was designed to be $14 \mathrm{~mm} \times 12$ $\mathrm{mm}$.

The fabrication of the MWCNT/HEC based humidity sensor was performed on the flexible PET substrate using screen and gravure printing processes. Fig. 4 shows the fabrication steps of the humidity sensor. Initially, the surface of the PET substrate was cleaned with isopropyl alcohol (IPA) and was heated at a temperature of $80^{\circ} \mathrm{C}$ for 2 hours on a VWR® Signature 810 hot plate to remove any organic impurities present on the surface of the substrate. Then, a semi-automatic screen printer (AMI MSP 485) was used to deposit Ag ink on the PET. A stainless steel screen, fabricated at Microscreen ${ }^{\circledR}$, with 325 mesh count, wire diameter $28 \mu \mathrm{m}$, mesh angle $22.5^{\circ}$ and $12.7 \mu \mathrm{m}$ thick MS-22 emulsion was used for screen printing. The printed Ag ink was thermally cured in a VWR 1320 temperature controlled oven at $135{ }^{\circ} \mathrm{C}$ for 5 minutes to form the Ag based IDTs. Finally, a laboratory scale gravure press (K-Printing Proofer) was used to deposit the FMWCNT/HEC ink on the IDTs as a humidity sensitive layer. An electromechanically engraved gravure plate, from IR Engraving LLC, with a 200 -line screen (LS) and $45^{\circ}$ cell angle was used for gravure printing. The printed FMWCNT/ HEC ink was thermally cured at $110{ }^{\circ} \mathrm{C}$ for 3 minutes. A photograph of the fabricated humidity sensor is shown in Fig. 5.

\subsection{Surface characterization of the printed layers}

A Bruker Contour GT-K vertical scanning interferometer was used to characterize the thickness and roughness of the printed layers (Fig. 6). An average thickness $(\Delta Z)$ of $1.49 \pm 0.05 \mu \mathrm{m}$ and $0.94 \pm 0.03 \mu \mathrm{m}$ and an average surface roughness (Sa) of $0.52 \pm$ $0.04 \mu \mathrm{m}$ and $0.28 \pm 0.05 \mu \mathrm{m}$ were obtained for the $\mathrm{Ag}$ electrodes and FMWCNT/HEC sensing layer, respectively. 


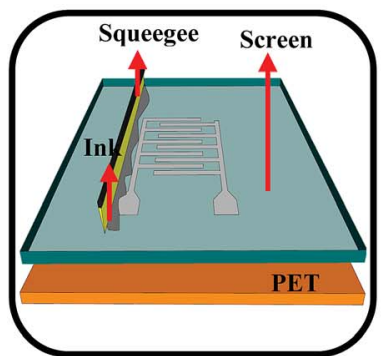

(a)

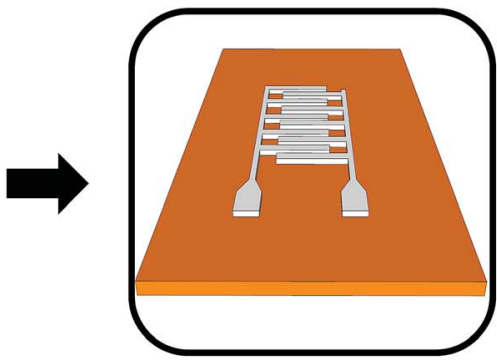

(b)

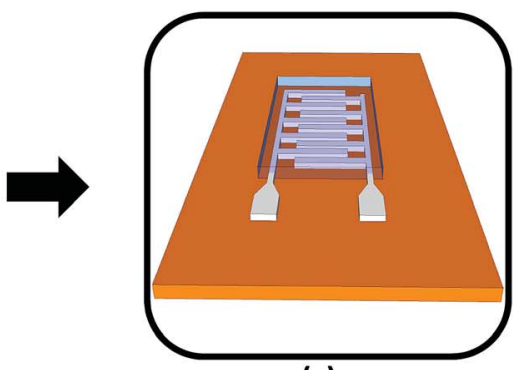

(c)

Fig. 4 (a) Screen printing of Ag ink on the PET substrate, (b) screen printed IDTs and (c) gravure printing of the MWCNT/HEC ink on the electrodes (not to scale).

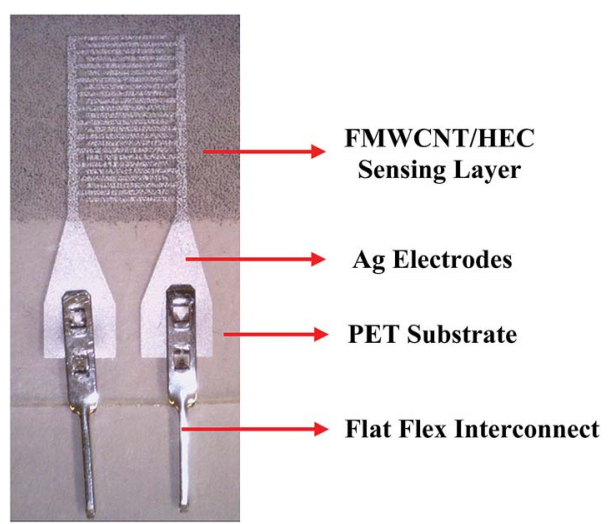

Fig. 5 Photograph of the printed sensor.

\subsection{Experimental setup}

The experimental setup for investigating the response of the printed humidity sensor towards varying relative humidity (\% $\mathrm{RH}$ ) is shown in Fig. 7. Electrical connections to the printed sensor were made using the FFCs. The printed sensor was subjected to relative humidity varying from $20 \% \mathrm{RH}$ to $80 \% \mathrm{RH}$, in steps of $10 \% \mathrm{RH}$, at a constant temperature of $25{ }^{\circ} \mathrm{C}$ in a Thermotron $\circledast$ SE 3000 environmental chamber. The chamber was equipped with a Thermotron ${ }^{\circledR} 8800$ data acquisition (DAQ) system for controlling, monitoring, graphing and reporting environmental chamber data. The relative humidity and temperature of the chamber were recorded using an integrated humidity sensor HUMICAP 180 from Vaisala and a T-type (Copper/Constantan) thermocouple $(\mathrm{T}-20 \mathrm{~B} / \mathrm{W})$, respectively. During the experiment, an Agilent E4980A precision LCR meter, controlled by a custom-built LabVIEW ${ }^{\mathrm{TM}}$ program on a PC, was used to record the resistance of the printed humidity sensor at an operating frequency of $1 \mathrm{kHz}$ and an applied voltage of $1 \mathrm{~V}$. (a)

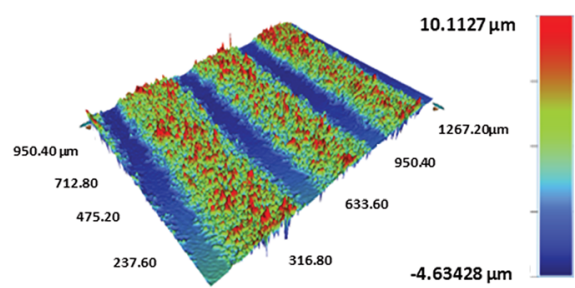

$\Delta \mathrm{Z}=\mathbf{1 . 5 3 \mu \mathrm { m }}$

(c)

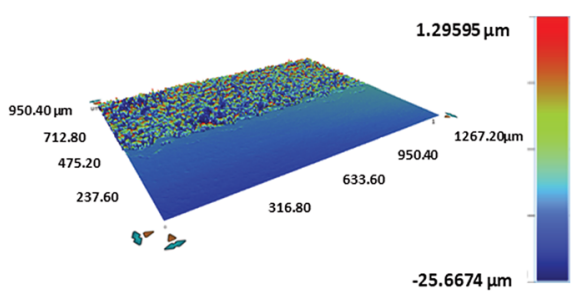

$\Delta \mathrm{Z}=0.92 \mu \mathrm{m}$ (b)

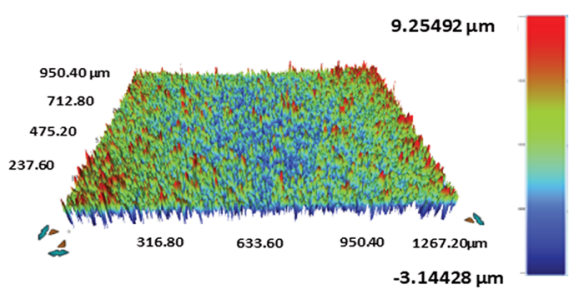

$\mathrm{Sa}=0.49 \mu \mathrm{m}$

(d)

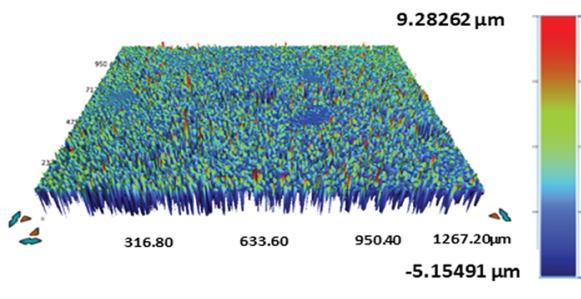

$\mathrm{Sa}=0.24 \mu \mathrm{m}$

Fig. 6 3D output of the vertical scanning interferometry showing the (a) thickness and (b) roughness of silver electrodes and the (c) thickness and (d) roughness of the FMWCNT/HEC sensing layer. 


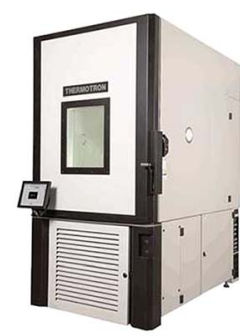

Thermotron ${ }^{\circledR}$ SE - 3000 Environmental Chamber

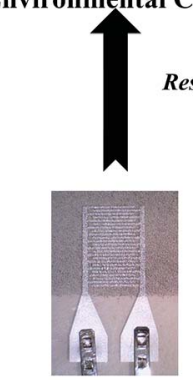

Printed Humidity Sensor

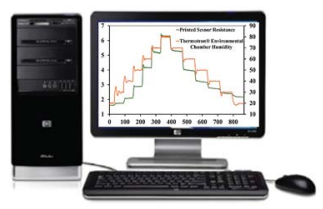

PC with LabVIEWTM

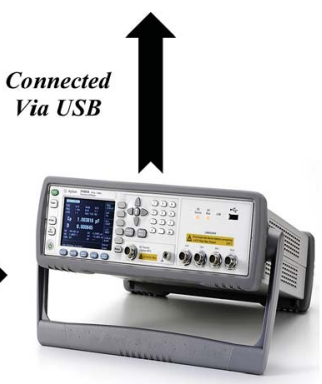

Agilent E4980a Precision LCR Meter
Fig. 7 Experimental setup.

\section{Results and discussion}

\subsection{Transmission electron microscopy (TEM)}

The TEM micrographs of the MWCNTs and FMWCNTs, which indicate a tube-like morphology, are shown in Fig. 7 and 8 , respectively. It was observed that the ends of the nanotubes were closed due to the presence of amorphous carbonaceous impurities around the MWCNTs (Fig. 7). Large agglomerates $(\approx 80-90 \mathrm{~nm}$ ) of MWCNTs were present due to van der Waal's forces of attraction..$^{\mathbf{2 0 , 4 2}}$ The diameter and length of the MWCNTs were measured to be in the range of $\approx 20 \mathrm{~nm}$ to $30 \mathrm{~nm}$ (Fig. 8(a)) and $\approx 8 \mu \mathrm{m}$ to $17 \mu \mathrm{m}$ (Fig. 8(b)), respectively.
The acid treatment of the MWCNTs enhanced the arrangement of tubes resulting in less agglomeration of the MWCNTs and removal of the carbonaceous impurities due to which the ends of the MWCNTs opened (marked with a red circle) (Fig. 9). This phenomenon is consistent with results obtained by Cao et al. and Rahmam et al. ${ }^{\mathbf{2 0 , 4 3}}$ It was observed that, after the acid treatment, the diameter and length of the FMWCNTs were in the range of $10 \mathrm{~nm}$ to $20 \mu \mathrm{m}$ and $0.1 \mu \mathrm{m}$ to $1 \mu \mathrm{m}$, respectively. The reduction in the length of the FMWCNTs can be attributed to the oxidative etching during the acid treatment. In addition, the acid treatment also introduced "defects" on the outermost walls of the MWCNTs, which indicates the presence of functional groups that make the FMWCNTs more hydrophilic ${ }^{51}$ (Fig. S3†).

\subsection{Raman spectroscopy}

Fig. 10 shows the Raman spectra of MWCNTs and FMWCNTs. Two characteristic peaks of MWCNTs corresponding to the graphite band (G-band) and the disorder/defect band (D-band) were observed in the high-frequency region of the spectra for both MWCNTs and FMWCNTs; at $\approx 1320 \mathrm{~cm}^{-1}$ and $\approx 1613 \mathrm{~cm}^{-1}$, respectively. ${ }^{44,52}$ The relative intensity $\left(I_{(\mathrm{D}) /(\mathrm{G})}\right)$, which is the ratio of the D-band intensity $\left(I_{(\mathrm{D})}\right)$ to the G-band intensity $\left(I_{(\mathrm{D})}\right)$, provides information on the degree of functionalization. $I_{(\mathrm{D}) /(\mathrm{G})}$ values of 1.05 and 1.33 were calculated for the MWCNTs and FMWCNTs, respectively, indicating that there was a $27 \%$ increase in the number of defective sites on the surface of the FMWCNTs. The increase in the number of defects can be attributed to the acid functionalization process that breaks the bond between the $\mathrm{C}=\mathrm{C}$ atoms and inserts functional groups. ${ }^{4,53}$

\subsection{Fourier transform infrared spectroscopy}

Fig. 11 shows the FT-IR spectra of both MWCNTs and FMWCNTs. In MWCNTs, the difference of charge states between carbon atoms is known to induce the formation of electric dipoles, when subjected to infrared radiation (IR). ${ }^{54}$

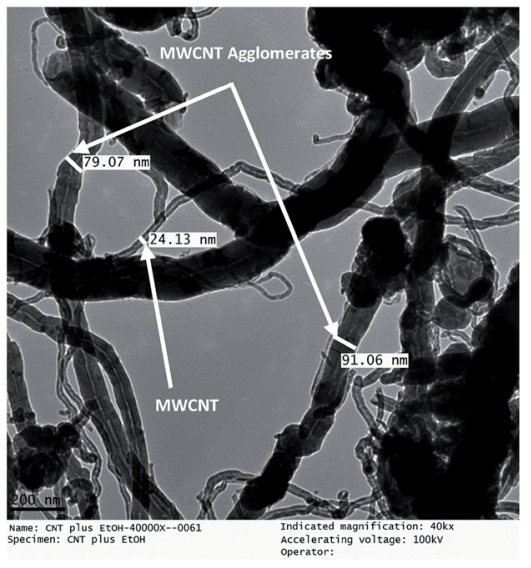

(a)

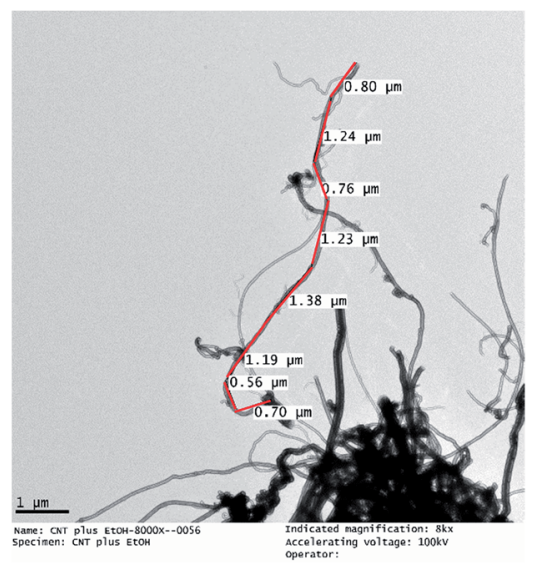

(b)

Fig. 8 TEM micrographs of MWCNTs showing (a) a diameter of $\approx 20-30 \mathrm{~nm}$ for the MWCNTs and a diameter of $\approx 80-90 \mathrm{~nm}$ for the MWCNT agglomerates, and (b) a length of $\approx 8-17 \mu \mathrm{m}$ for the MWCNTs. 


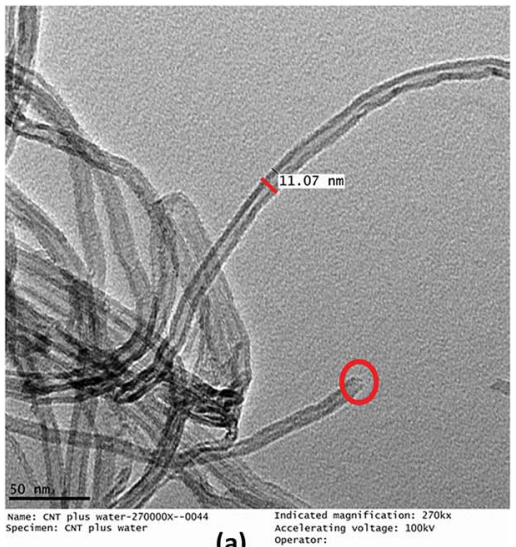

(a)

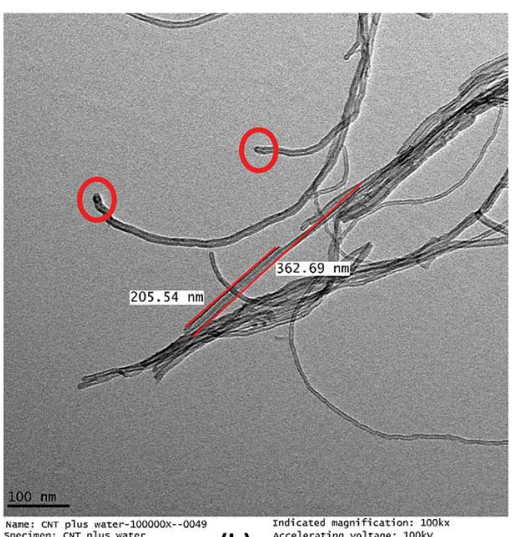

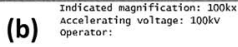

Fig. 9 TEM micrographs of FMWCNTs showing (a) a diameter of 10-20 nm (marked in red circles) and (b) a length of 0.1-1 $\mu \mathrm{m}$.

Raman Spectra of MWCNT

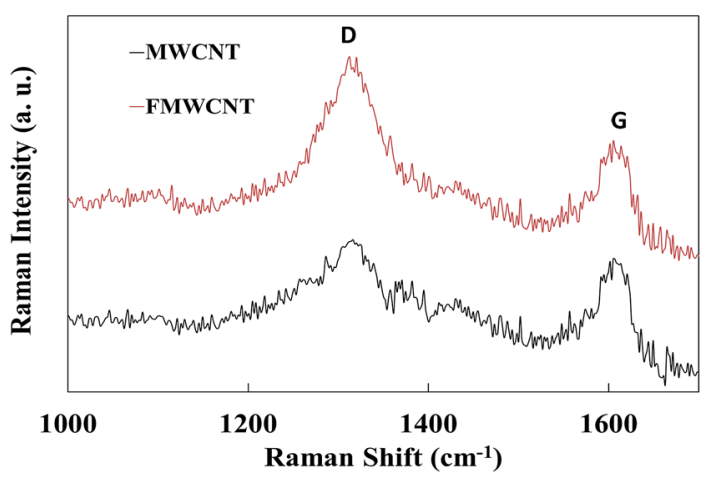

Fig. 10 Raman spectra of MWCNTs and FMWCNTs.

These dipoles can be detected as the IR spectra during the FT-IR analysis. ${ }^{\mathbf{4 4 5 4}}$ In MWCNTs, the symmetrical structure results in a relatively silent spectrum as weak infrared signals are detected due to the weak difference of charge states between the symmetrical carbon atoms. ${ }^{\mathbf{4 4}}$ However, in the FMWCNTs, multiple characteristic peaks were observed in the FT-IR spectra indicating the presence of functional groups that are

\section{FT-IR Spectra of MWCNT}

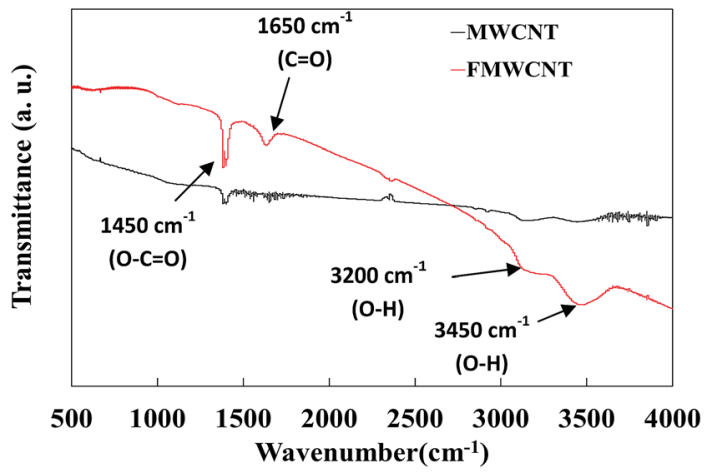

Fig. 11 FT-IR spectra of the MWCNTs and FMWCNTs. introduced due to the acid treatment. Broad peaks between $3000 \mathrm{~cm}^{-1}$ and $3500 \mathrm{~cm}^{-1}$ were obtained indicating the characteristic stretching vibrations of hydroxyl $(\mathrm{O}-\mathrm{H})$ bonds. $^{\mathbf{4 4}}$ Further, the FT-IR spectrum of the FMWCNTs showed the peaks of carboxyl $(\mathrm{C}=\mathrm{O})$ and carbonyl $(\mathrm{O}-\mathrm{C}=\mathrm{O})$ groups at $\approx 1650 \mathrm{~cm}^{-1}$ and $\approx 1450 \mathrm{~cm}^{-1}$, respectively. ${ }^{44,55,56}$ Thus, these peaks from the FT-IR indicated the presence of functional groups on the surface of FMWCNTs after covalent acid functionalization.

\subsection{Dispersion analysis}

The results of the dispersion analysis for the MWCNTs and FMWCNTs are shown in Fig. S4. $†$ Vigorously stirred solutions of the MWCNTs and FMWCNTs $(0.5 \mathrm{wt} \%)$ in DI water were held for up to 5 days to investigate their suspension stability. Sedimentation of the MWCNTs was observed, within 60 seconds, which demonstrated poor suspension stability. This sedimentation occurred due to the agglomeration of the MWCNTs, caused by van der Waal's forces of attraction. ${ }^{44}$ On the other hand, the FMWCNTs showed better suspension stability for up to 5 days, as no sedimentation was observed. This stability is due to the presence of the equally charged functional hydroxyl and carboxyl groups which enable the MWCNTs to repel each other and, thus, keep the solution dispersed. ${ }^{\mathbf{4 4}}$

\subsection{Humidity sensor characterization}

Before subjecting the humidity sensors to varying humidity levels, the sensors were pre-heated on a VWR 810 ceramic hot plate at $90{ }^{\circ} \mathrm{C}$ for 1 hour to remove the water molecules trapped around the FMWCNTs and in between the electrodes. Fig. 12 shows the relative resistive response of printed humidity sensors fabricated using different ink compositions. The content of the FMWCNTs was varied from $1.25 \mathrm{wt} \%$ to $2.5 \mathrm{wt} \%$ in the ink, with respect to the solvent and the weight ratio between FMWCNTs and HEC was varied from $1: 4$ to $1: 6$. It was observed that the printed humidity sensor fabricated with 1.25 wt\% FMWCNTs (FMWCNTs : HEC: 1:6) yielded a maximum relative resistive response of 0.82 , at $80 \% \mathrm{RH}$. By maintaining the content of the FMWCNTs at $1.25 \mathrm{wt} \%$ and 


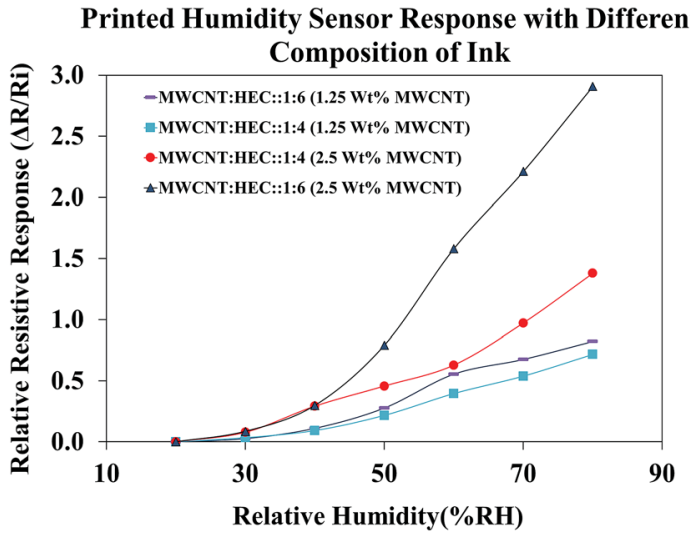

Fig. 12 Response of the humidity sensor with different compositions of the FMWCNT/HEC ink.

decreasing the ratio between the FMWCNTs and HEC to $1: 4$, the maximum relative resistive response of the sensor decreased to 0.71 , at $80 \% \mathrm{RH}$. This decrease in maximum relative resistive response can be attributed to the lower HEC content. Further, with increasing the content of the FMWCNTs to $2.5 \mathrm{wt} \%$ and maintaining the ratio of FMWCNTs and HEC at $1: 4$, the maximum relative resistive response of the printed sensor increased to 1.37 , at $80 \% \mathrm{RH}$. This is due to the availability of more FMWCNTs for the adsorption of water molecules on their surface. By elevating the ratio of the FMWCNTs and HEC to $1: 6$, the maximum relative resistive response of the printed sensor increased to a relatively higher value of 2.91, indicating that the relative resistive response of the printed humidity sensor can be tunable by varying the ink composition. The ink with $2.5 \mathrm{wt} \%$ FMWCNTs (FMWCNTs : HEC: $1: 6$ ), which had the highest maximum relative resistive response, was chosen for further evaluation in this study.

Fig. 13(a) shows the dynamic resistive response of the printed sensor towards varying relative humidity. The humidity of the chamber was varied form $20 \% \mathrm{RH}$ to $80 \% \mathrm{RH}$ during the humidification process and from $80 \% \mathrm{RH}$ to $20 \% \mathrm{RH}$ during the de-humidification process, in steps of $10 \% \mathrm{RH}$ at a constant temperature of $25{ }^{\circ} \mathrm{C}$. Accordingly, the resistance of the humidity sensor increased during the humidification process and recovered back during the de-humidification process, over time. The humidity sensing mechanism of the FMWCNT/HEC is based on the electron donation model of the MWCNTs and swelling behavior of the HEC. The MWCNT network exhibits ptype semiconducting characteristics, where the electrical conduction is dominated by holes. ${ }^{57}$ When exposed to humidity in the environment, the resistance changes in the MWCNTs depend on their interaction with water molecules. These water molecules are adsorbed onto the surface of the MWCNTs through physisorption, and tend to transfer electrons to MWCNTs due to the difference in electrical potential between them. ${ }^{19,58}$ This charge transfer mechanism decreases the number of holes and consequently increases the electrical resistance of MWCNTs. The RH level of the environment directly dictates the amount of water molecules to be adsorbed

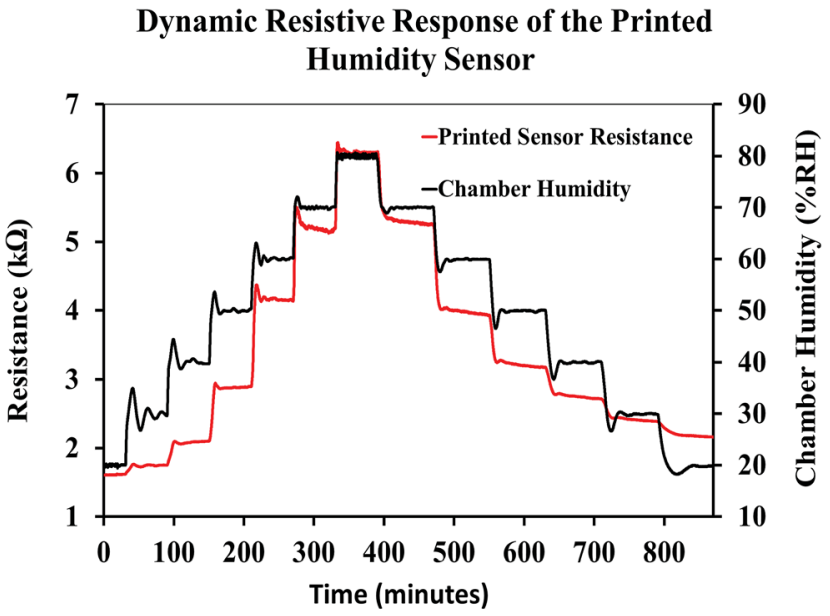

(a)

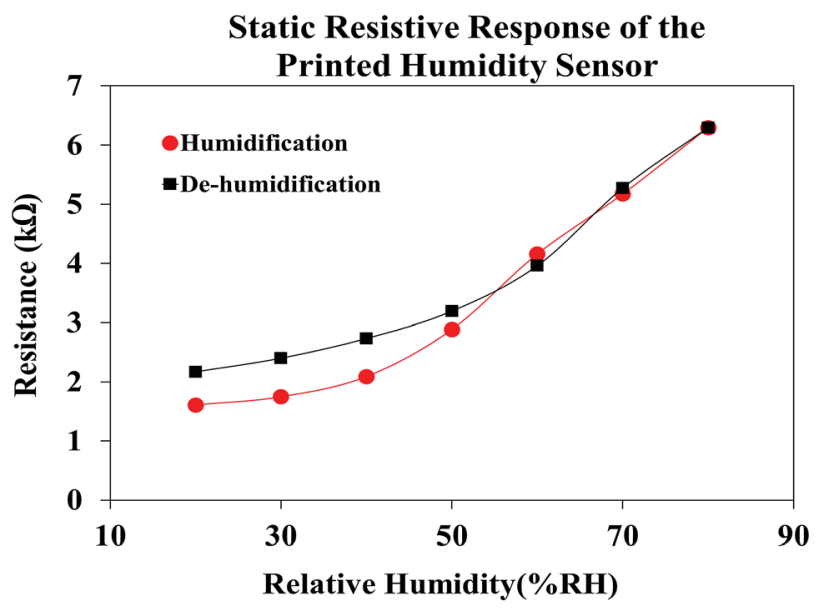

(b)

Fig. 13 (a) Dynamic and (b) static response of the printed humidity sensor.

on the MWCNTs. As the RH level increases, more water molecules are adsorbed, and more electrons will be transferred, leading to a further increase in the resistance value. ${ }^{11}$ In addition, the hydroxyl and carboxyl groups present on the defective sites of the FMWCNTs show increased affinity towards water molecules (hydrophilicity). This improved hydrophilicity not only enhances the interaction between FMWCNTs and water molecules, but also aids in increasing the number of electrons transferred, contributing to a much higher resistance change. ${ }^{11}$ Further, the HEC consists of abundant hydroxyl groups and exhibits physical swelling upon exposure to humidity due to the adsorption of a large number of water molecules. ${ }^{59}$ This swelling property of HEC can effectively increase the contact gap of the FMWCNT intertube junction in the composite, thereby contributing to the increase in the resistance with humidification. ${ }^{11}$ However, during de-humidification the number of effective charge carriers (holes) in the FMWCNTs increases as the water molecules desorb from their surface. ${ }^{64}$ This increase in the number of effective charge carriers results in a decrease in the resistance values. In addition, HEC starts to physically 
shrink as the water molecules desorb from its surface. ${ }^{65}$ This phenomenon decreases the contact gap of the FMWCNT intertube junction in the composite, hence resulting in a decrease in the resistance during dehumidification.

Fig. 13(b) shows the average static resistive response of the printed humidity sensor. It was observed that during the humidification process, the resistance of the sensors increased from $1.6 \mathrm{k} \Omega$ to $6.3 \mathrm{k} \Omega$, when the relative humidity in the chamber was varied from $20 \% \mathrm{RH}$ to $80 \% \mathrm{RH}$. This resulted in an overall resistance change of $\approx 290 \%$ at $80 \% \mathrm{RH}$, when compared to the base resistance at $20 \% \mathrm{RH}$. A sensitivity $(S)$ of $0.0485 / \%$ RH was mathematically calculated for the fabricated humidity sensor using eqn (1).

$$
S=\left(\frac{1}{\left(R_{\mathrm{T}_{\mathrm{i}}}\right)}\right) \frac{\left(R_{\mathrm{T}_{\mathrm{i}}}-R_{\mathrm{T}_{\mathrm{f}}}\right)}{\left(\mathrm{RH}_{\mathrm{i}}-\mathrm{RH}_{\mathrm{f}}\right)}
$$

where $R_{\mathrm{T}_{\mathrm{i}}}$ and $R_{\mathrm{T}_{\mathrm{f}}}$ are the resistance values obtained at initial relative humidity $\mathrm{RH}_{\mathrm{i}}$ and final temperature $\mathrm{RH}_{\mathrm{f}}$. The results obtained for the printed humidity sensor demonstrated a sensitivity which is an order of magnitude greater than the sensitivity of a MWCNT network-based humidity sensor $(0.005 / \% \mathrm{RH})$ reported by Liu et al. ${ }^{19}$ In addition, the sensitivity of the printed FMWCNT/HEC based humidity sensor was better than those of several other MWCNT and MWCNT/polymerbased humidity sensors reported ${ }^{\mathbf{1 5 , 1 9 , 2 0 , 6 0 - 6 2}}$ and a comparison is shown in Table 1 . It was observed that the printed humidity sensor exhibited a hysteresis effect at low moisture levels during humidification/de-humidification. This hysteresis can be attributed to the charge trapping by water molecules present around FMWCNTs, especially with their improved hydrophilicity. ${ }^{66}$ The trapped charge contributes to a comparatively higher resistance, during de-humidification when compared to the resistance, during humidification.

The reproducibility of the sensor performance was investigated by analyzing the resistive response of three different sensors printed using the FMWCNT/HEC ink, formulated separately for each sensor (Fig. 14). It was observed that all three fabricated sensors demonstrated a similar response towards relative humidity varying from $20 \% \mathrm{RH}$ to $80 \% \mathrm{RH}$, yielding an average maximum resistance change of $273 \% \pm 21 \%$ at $80 \%$ $\mathrm{RH}$, when compared to base resistance at $20 \% \mathrm{RH}$. The obtained results prove the reproducibility of both the FMWCNT/ HEC ink and the printed humidity sensor.

The response curve of the printed humidity sensor is shown in Fig. 15(a). It was observed that the resistive response of the

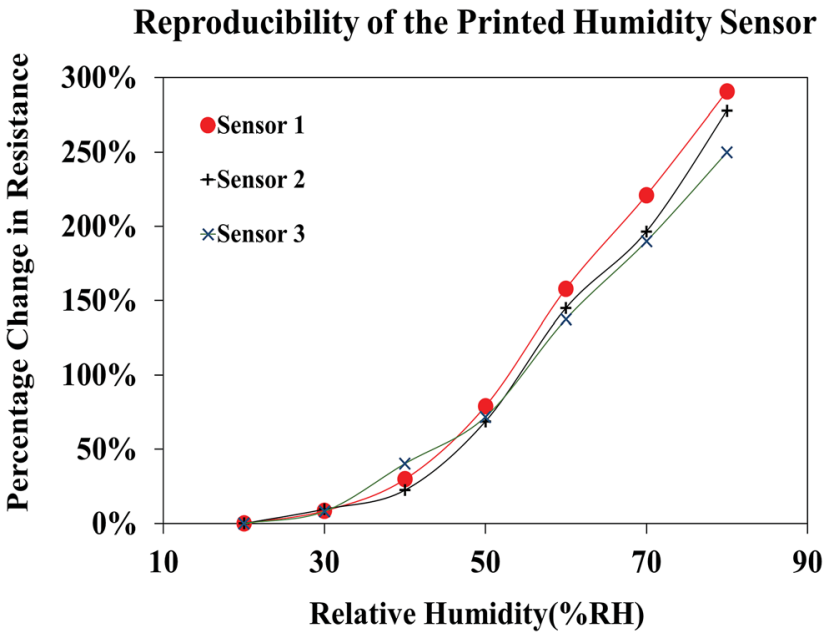

Fig. 14 Reproducibility of the humidity sensor.

printed sensor followed the response of the integrated humidity sensor (HUMICAP 180, Vaisala) in the environmental chamber, when the relative humidity of the chamber was varied from $50 \%$ $\mathrm{RH}$ to $60 \% \mathrm{RH}$. Since the response time of the integrated humidity sensor is less than 20 seconds, the response time of the printed humidity sensor was estimated to be $\approx 20$ seconds and is comparable with the performance of conventional impedance type humidity sensors, which typically ranges from 10 seconds to 30 seconds. ${ }^{6,63}$ The recovery curve of the printed humidity sensor when the relative humidity of the chamber was varied from $60 \% \mathrm{RH}$ to $50 \% \mathrm{RH}$ is shown in Fig. 15(b). The recovery time of the printed humidity sensor was estimated to be $\approx 35$ seconds and is also comparable with those of conventional impedance type humidity sensors, which typically range from 15 seconds to 35 seconds. $^{6}$

Fig. 16(a) shows the transient response of the printed humidity sensor demonstrating dynamic humidification and de-humidification cycles. The relative humidity in the chamber was interchanged between $20 \% \mathrm{RH}$ and $80 \% \mathrm{RH}$, at a constant relative temperature of $25{ }^{\circ} \mathrm{C}$, and the response of the printed sensor followed the interchangeability with increase and decrease in the resistance values. Throughout this experiment, the printed sensor yielded a consistent maximum resistive change of $\approx 290 \%$, thus demonstrating the repeatability of the printed sensor. In addition, the stability of the printed humidity sensor, over time, was investigated by recording its resistive

Table 1 Comparison of sensitivity between the printed FMWCNT/HEC humidity sensor and other reported printed sensors

\begin{tabular}{|c|c|c|c|c|c|}
\hline Author & Materials & Sensitivity & Response time & Recovery time & Ref. \\
\hline Liu et al. (2009) & MWCNT network & $0.0056 / \% \mathrm{RH}$ & $3 \mathrm{~s}$ & $25 \mathrm{~s}$ & 19 \\
\hline Yu et al. (2006) & PEI/MWCNT film & $0.0099 / \% \mathrm{RH}$ & $2 \mathrm{~s}$ & $30 \mathrm{~s}$ & 60 \\
\hline Cao et al. (2011) & Acid treated MWCNT film & $0.0154 / \% \mathrm{RH}$ & $50 \mathrm{~s}$ & $140 \mathrm{~s}$ & 20 \\
\hline Yoo et al. (2010) & $\mathrm{O}_{2}$ plasma-treated PI/MWCNT film & $0.0047 / \% \mathrm{RH}$ & Not reported & Not reported & 15 \\
\hline Tang et al. (2011) & PI/MWCNT film & $0.0018 / \% \mathrm{RH}$ & Less than $5 \mathrm{~s}$ & Not reported & 61 \\
\hline Chu et al. (2013) & Carbon nanosheet based sensor & $0.0268 / \% \mathrm{RH}$ & $30 \mathrm{~s}$ & $90 \mathrm{~s}$ & 62 \\
\hline Turkani et al. (2018) & Functionalized MWCNT/HEC & $0.0485 / \% \mathrm{RH}$ & $\approx 20 \mathrm{~s}$ & $\approx 35 \mathrm{~s}$ & Present work \\
\hline
\end{tabular}




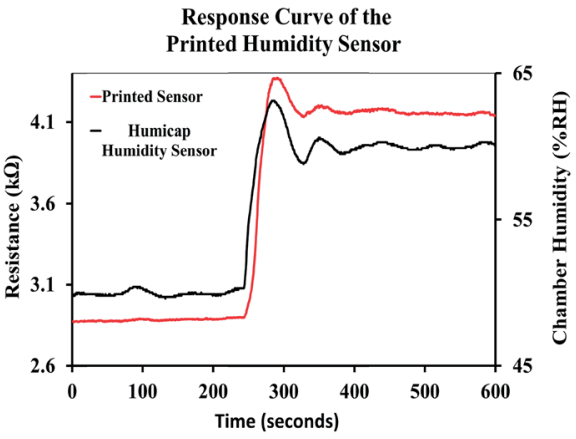

(a)

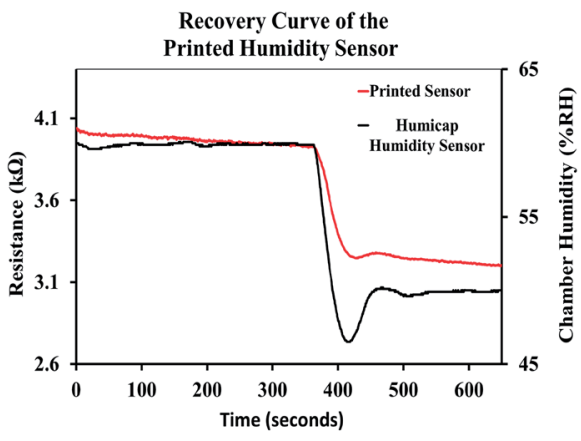

(b)

Fig. 15 (a) Response curve and (b) recovery curve of the printed humidity sensor.

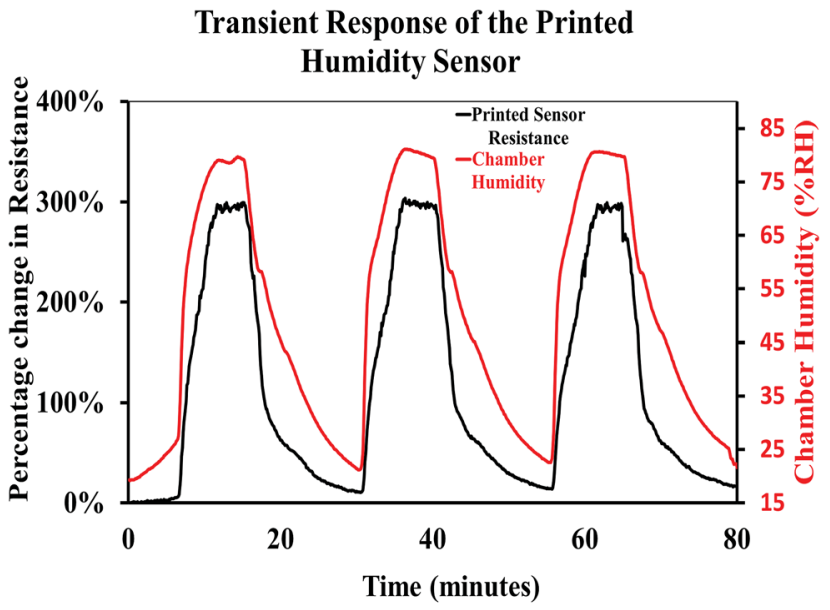

(a)

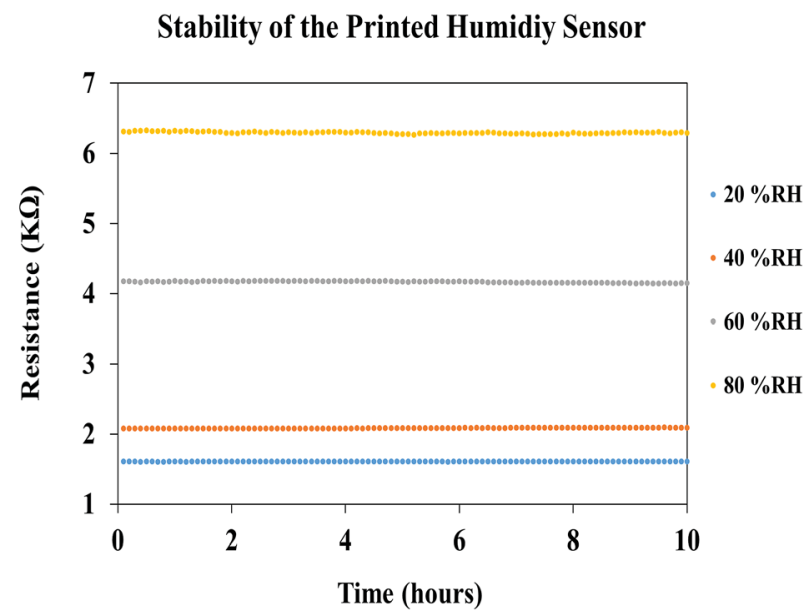

(b)

Fig. 16 (a) Transient response of the printed humidity sensor and (b) stability of the printed humidity sensor.

response at different relative humidities $(20 \% \mathrm{RH}, 40 \% \mathrm{RH}$, $60 \% \mathrm{RH}$, and $80 \% \mathrm{RH}$ ), for a period of 10 hours (Fig. 16(b)), at a constant chamber temperature of $25{ }^{\circ} \mathrm{C}$. A drift of $0.10 \%$, $0.16 \%, 25 \%, 0.28 \%$ and $0.21 \%$ in the resistance was observed for a constant relative humidity of $20 \% \mathrm{RH}, 40 \% \mathrm{RH}, 60 \% \mathrm{RH}$, and $80 \% \mathrm{RH}$, respectively. It was observed that the printed humidity sensor was capable of sensing a broad range of relative humidities (20\% RH to $80 \% \mathrm{RH}$ ) while demonstrating good stability over time. From the results obtained, it is evident that the printed humidity sensor has the capability to be employed for humidity sensing applications in the automobile, laboratory and food industries.

\section{Conclusion}

In this work, a fully printed, highly sensitive, humidity sensor based on a FMWCNT and HEC composite was successfully developed for humidity monitoring applications. To enhance the hydrophilicity, MWCNTs were treated in a mixture of sulfuric and nitric acid. Transmission electron microscopy, Raman spectroscopy, Fourier transform infrared spectroscopy and dispersion analysis were performed to confirm the functionalization and the presence of functional groups on the surface of the MWCNTs. A FMWCNT/HEC composite ink was formulated with $2.5 \mathrm{wt} \%$ MWCNTs and the ratio between FMWCNTs and HEC was maintained at 1:6. A pair of electrodes with 24 fingers in an interdigitated geometry were deposited using the screen printing process. The formulated FMWCNT/HEC ink was deposited on the electrodes as the sensing layer using the gravure printing process. The performance of the printed humidity sensor was investigated by measuring its resistive response towards relative humidity varying from $20 \% \mathrm{RH}$ to $80 \% \mathrm{RH}$, in steps of $10 \% \mathrm{RH}$, at a constant temperature of $25{ }^{\circ} \mathrm{C}$. The printed sensor exhibited resistive changes as high as $290 \%$ at $80 \% \mathrm{RH}$, when compared to its base resistance at $20 \% \mathrm{RH}$ with a sensitivity of $0.048 / \% \mathrm{RH}$. The obtained sensitivity of the sensor was greater than those of several other MWCNT and MWCNT/polymer based humidity sensors reported. The reproducibility in terms of ink formulation and fabrication of sensors was also investigated. In addition, the printed humidity sensor demonstrated a good response time of $\approx 20 \mathrm{~s}$ when measured against a commercial humidity sensor equipped in the environmental chamber.

These results demonstrate that humidity sensors fabricated using additive print manufacturing processes on flexible substrates, with the FMWCNT/HEC composite as the sensing 
material, have a significant potential in humidity sensing applications. Moreover, the printed humidity sensor can potentially be implemented in applications where its lightweight and conformal features along with large scale manufacturing capabilities are paramount for improved userdevice interactions. Further research is underway to investigate the performance of the printed humidity sensor for varying temperatures along with the compensation strategies. Research is also being focused on the monolithic integration of a printed micro-heater with the humidity sensor and, thereby, the improvement of the reliability of the sensor by reducing the hysteresis. Finally, the effect of mechanical stresses such as bending, twisting, and stretching on the performance of the sensor is also under investigation to determine appropriate output compensation required, before implementing the printed humidity sensor into a field deployable sensing system.

\section{Conflicts of interest}

There are no conflicts to declare.

\section{Acknowledgements}

V. S. Turkani acknowledges the Graduate Research Grant Award from the Graduate College, Western Michigan University (WMU). We acknowledge the Center for Advanced Smart Sensors and Structures, WMU for letting us use the screen and gravure printers to fabricate the sensors. We also acknowledge the CAViDS Hybrid Electric Applied Research Lab and Dr Claudia Fajardo for letting us use their Thermotron ${ }^{\circledR}$ environmental chamber. We acknowledge Mathew Stoops for his contribution to this study.

\section{References}

1 B. Patissier, Sens. Actuators, B, 1999, 59, 231-234.

2 W. Vautz, J. I. Baumbach, M. Westhoff, K. Züchner, E. T. H. Carstens and T. Perl, Int. J. Ion Mobility Spectrom., 2010, 13, 41-46.

3 E. Abad, F. Palacio, M. Nuin, A. G. D. Zárate, A. Juarros, J. Gómez and S. Marco, J. Food Eng., 2009, 93, 394-399.

4 E. Tan, W. Ng, R. Shao, B. Pereles and K. Ong, Sensors, 2007, 7, 1747-1756.

5 B. M. Kulwicki, J. Am. Ceram. Soc., 1991, 74, 697-708.

6 H. Farahani, R. Wagiran and M. Hamidon, Sensors, 2014, 14, 7881-7939.

7 N. Yamazoe and Y. Shimizu, Sens. Actuators, 1986, 10, 379398.

8 M. Packirisamy, I. Stiharu, X. Li and G. Rinaldi, Sens. Rev., 2005, 25, 271-276.

9 M. Matsuguchi, T. Kuroiwa, T. Miyagishi, S. Suzuki, T. Ogura and Y. Sakai, Sens. Actuators, B, 1998, 52, 53-57.

10 J.-H. Kim, S.-M. Hong, J.-S. Lee, B.-M. Moon and K. Kim, 2009 4th IEEE International Conference on Nano/Micro Engineered and Molecular Systems, 2009.

11 D. Wang, Y. Huang, Y. Ma, P. Liu, C. Liu and Y. Zhang, J. Mater. Res., 2014, 29, 2845-2853.
12 P.-G. Su and C.-S. Wang, Sens. Actuators, B, 2007, 123, 10711076.

13 D.-I. Lim, J.-R. Cha and M.-S. Gong, Sens. Actuators, B, 2013, 183, 574-582.

14 M. Ueda, K. Nakamura, K. Tanaka, H. Kita and K.-I. Okamoto, Sens. Actuators, B, 2007, 127, 463-470.

15 K.-P. Yoo, L.-T. Lim, N.-K. Min, M. J. Lee, C. J. Lee and C.-W. Park, Sens. Actuators, B, 2010, 145, 120-125.

16 S. Iijima, Nature, 1991, 354, 56-58.

17 J. Suehiro, G. Zhou and M. Hara,J. Phys. D: Appl. Phys., 2003, 36, L109.

18 M. Atashbar, B. Bejcek and S. Singamaneni, IEEE Sens. J., 2006, 6, 524-528.

19 L. Liu, X. Ye, K. Wu, R. Han, Z. Zhou and T. Cui, Sensors, 2009, 9, 1714-1721.

20 C. L. Cao, C. G. Hu, L. Fang, S. X. Wang, Y. S. Tian and C. Y. Pan, J. Nanomater., 2011, 2011, 1-5.

21 Z. Imran, S. Batool, H. Jamil, M. Usman, M. Israr-Qadir, S. Shah, S. Jamil-Rana, M. Rafiq, M. Hasan and M. Willander, Ceram. Int., 2013, 39, 457-462.

22 P. K. Kannan, R. Saraswathi and J. B. B. Rayappan, Sens. Actuators, A, 2010, 164, 8-14.

23 J. Gao, J. Siden, H.-E. Nilsson and M. Gulliksson, IEEE Sens. J., 2013, 13, 1824-1834.

24 V. Sanchez-Romaguera, S. Wünscher, B. M. Turki, R. Abbel, S. Barbosa, D. J. Tate, D. Oyeka, J. C. Batchelor, E. A. Parker, U. S. Schubert and S. G. Yeates, J. Mater. Chem. C, 2015, 3, 2141-2142.

25 T. Vuorinen, M.-M. Laurila, R. Mangayil, M. Karp and M. Mäntysalo, EMBEC \& NBC 2017 IFMBE Proceedings, 2017, pp. 839-842.

26 S. Yao and Y. Zhu, Nanoscale, 2014, 6, 2345.

27 A. S. G. Reddy, B. B. Narakathu, M. Z. Atashbar, M. Rebros, E. Rebrosova, B. J. Bazuin, M. K. Joyce, P. D. Fleming and A. Pekarovicova, Sens. Lett., 2011, 9, 869-871.

28 S. Emamian, B. B. Narakathu, A. A. Chlaihawi, B. J. Bazuin and M. Z. Atashbar, Sens. Actuators, A, 2017, 263, 639-647.

29 A. A. Chlaihawi, S. Emamian, B. B. Narakathu, M. M. Ali, D. Maddipatla, B. J. Bazuin and M. Z. Atashbar, Sens. Actuators, A, 2017, 268, 1-8.

30 S. G. R. Avuthu, J. T. Wabeke, B. B. Narakathu, D. Maddipatla, J. S. Arachchilage, S. O. Obare and M. Z. Atashbar, IEEE Sens. J., 2016, 16, 8678-8684.

31 B. B. Narakathu, S. G. R. Avuthu, A. Eshkeiti, S. Emamian and M. Z. Atashbar, IEEE Sens. J., 2015, 15, 6374-6380.

32 S. Emamian, A. Eshkeiti, B. B. Narakathu, S. G. R. Avuthu and M. Z. Atashbar, Sens. Actuators, B, 2015, 217, 129-135.

33 B. B. Narakathu, M. S. Devadas, A. S. G. Reddy, A. Eshkeiti, A. Moorthi, I. R. Fernando, B. P. Miller, G. Ramakrishna, E. Sinn, M. Joyce, M. Rebros, E. Rebrosova, G. Mezei and M. Z. Atashbar, Sens. Actuators, B, 2013, 176, 768-774.

34 A. Eshkeiti, B. B. Narakathu, A. S. G. Reddy, A. Moorthi and M. Z. Atashbar, Sens. Actuators, B, 2012, 171, 705-711.

35 G. A. D. R. Benatto, B. Roth, M. Corazza, R. R. Søndergaard, S. A. Gevorgyan, M. Jørgensen and F. C. Krebs, Nanoscale, 2016, 8, 318-326. 
36 D. Angmo, T. R. Andersen, J. J. Bentzen, M. Helgesen, R. R. Søndergaard, M. Jørgensen, J. E. Carlé, E. Bundgaard and F. C. Krebs, Adv. Funct. Mater., 2015, 25, 4539-4547.

37 H. Zhu, B. B. Narakathu, Z. Fang, A. T. Aijazi, M. Joyce, M. Atashbar and L. Hu, Nanoscale, 2014, 6, 9110.

38 K.-S. Kim, K.-H. Jung and S.-B. Jung, Microelectron. Eng., 2014, 120, 216-220.

39 A. Eshkeiti, A. S. G. Reddy, S. Emamian, B. B. Narakathu, M. Joyce, M. Joyce, P. D. Fleming, B. J. Bazuin and M. Z. Atashbar, IEEE Trans. Compon., Packag., Manuf. Technol., 2015, 5, 415-421.

40 V. S. Turkani, D. Maddipatla, B. B. Narakathu, B. J. Bazuin and M. Z. Atashbar, in 17th International Meeting on Chemical Sensors, IMCS Proceedings, 2018, pp. 519-520, DOI: $10.5162 /$ imcs2018/p1fw.5.

41 L. Xie, Y. Feng, M. Mäntysalo, Q. Chen and L. R. Zheng, IEEE Sens. J., 2013, 13(10), 3948-3956.

42 K. A. Wepasnick, B. A. Smith, K. E. Schrote, H. K. Wilson, S. R. Diegelmann and D. H. Fairbrother, Carbon, 2011, 49, 24-36.

43 S. Rahmam, N. M. Mohamed and S. Sufian, Mater. Res. Innovations, 2014, 18, S6-S196.

44 A. Osorio, I. Silveira, V. Bueno and C. Bergmann, Appl. Surf. Sci., 2008, 255, 2485-2489.

45 H. Menon, R. Aiswarya and K. P. Surendran, RSC Adv., 2017, 7, 44076-44081.

46 W. Wang, J. Wang, Y. Kang and A. Wang, Composites, Part B, 2011, 42, 809-818.

47 J. N. Israelachvili, Intermolecular and Surface Forces, Academic press, 2011, pp. 415-438.

48 A. Rudawska and J. Elżbieta, Int. J. Adhes. Adhes., 2009, 29(4), 451-457.

49 C. E. Stauffer, J. Phys. Chem., 1965, 69, 1933-1938.
50 Y. Yuan and T. R. Lee, Surface Science Techniques Springer Series in Surface Sciences, 2013, pp. 3-34.

51 M. Farbod, A. Zilaie and I. Kazeminezhad, Journal of Science: Advanced Materials and Devices, 2017, 2, 99-104.

52 M. Dresselhaus, G. Dresselhaus, A. Jorio, A. S. Filho and R. Saito, Carbon, 2002, 40, 2043-2061.

53 S. D. Kim, J. W. Kim, J. S. Im, Y. H. Kim and Y. S. Lee, J. Fluorine Chem., 2007, 128, 60-64.

54 A. Loiseau, P. Launois, P. Petit, S. Roche and J. P. Salvetat, Lect. Notes Phys., 2006, 677, 495-543.

55 M. Wongaree, S. Chiarakorn and S. Chuangchote, J. Nanomater., 2015, 2015, 1-10.

56 W. O. G., J. Mol. Struct., 1995, 372, 285.

57 O. Varghese, P. Kichambre, D. Gong, K. Ong, E. Dickey and C. Grimes, Sens. Actuators, B, 2001, 81, 32-41.

58 R. Pati, Y. Zhang, S. K. Nayak and P. M. Ajayan, Appl. Phys. Lett., 2002, 81, 2638-2640.

59 S. Muto, O. Suzuki, T. Amano and M. Morisawa, Meas. Sci. Technol., 2003, 14, 746-750.

60 H. Yu, T. Cao, L. Zhou, E. Gu, D. Yu and D. Jiang, Sens. Actuators, B, 2006, 119, 512-515.

61 Q.-Y. Tang, Y. Chan and K. Zhang, Sens. Actuators, B, 2011, 152, 99-106.

62 J. Chu, X. Peng, P. Feng, Y. Sheng and J. Zhang, Sens. Actuators, B, 2013, 178, 508-513.

63 Y. Sakai, Y. Sadaoka and M. Matsuguchi, Sens. Actuators, B, 1996, 35, 85-90.

64 Suspended carbon nanotubes for humidity sensing.

65 T. Fei, H. Zhao, K. Jiang, X. Zhou and T. Zhang, J. Appl. Polym. Sci., 2013, 130, 2056-2061.

66 W. Kim, A. Javey, O. Vermesh, Q. Wang, Y. Li and H. Dai, Nano Lett., 2003, 3, 193-198. 